\title{
Past and future conditions for polar stratospheric cloud formation simulated by the Canadian Middle Atmosphere Model
}

\author{
P. Hitchcock, T. G. Shepherd, and C. McLandress \\ Department of Physics, University of Toronto, Toronto, ON, Canada \\ Received: 12 June 2008 - Published in Atmos. Chem. Phys. Discuss.: 1 September 2008 \\ Revised: 11 December 2008 - Accepted: 11 December 2008 - Published: 21 January 2009
}

\begin{abstract}
We analyze here the polar stratospheric temperatures in an ensemble of three 150-year integrations of the Canadian Middle Atmosphere Model (CMAM), an interactive chemistry-climate model which simulates ozone depletion and recovery, as well as climate change. A key motivation is to understand possible mechanisms for the observed trend in the extent of conditions favourable for polar stratospheric cloud (PSC) formation in the Arctic winter lower stratosphere.

We find that in the Antarctic winter lower stratosphere, the low temperature extremes required for PSC formation increase in the model as ozone is depleted, but remain steady through the twenty-first century as the warming from ozone recovery roughly balances the cooling from climate change. Thus, ozone depletion itself plays a major role in the Antarctic trends in low temperature extremes.

The model trend in low temperature extremes in the Arctic through the latter half of the twentieth century is weaker and less statistically robust than the observed trend. It is not projected to continue into the future. Ozone depletion in the Arctic is weaker in the CMAM than in observations, which may account for the weak past trend in low temperature extremes. In the future, radiative cooling in the Arctic winter due to climate change is more than compensated by an increase in dynamically driven downwelling over the pole.
\end{abstract}

\section{Introduction}

Over the present century the ozone layer is expected to recover as the halogen loading of the stratosphere subsides. However, the particulars of this recovery will likely be influenced by climate change (e.g., Shepherd, 2008). Since ozone

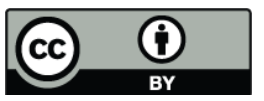

Correspondence to: P. Hitchcock (peterh@atmosp.physics.utoronto.ca) chemistry is strongly coupled to polar stratospheric temperatures which, in turn, are determined in part by dynamically driven downwelling in winter and spring, a clear understanding of the determinants of these temperatures is critical to a complete understanding of how the ozone layer will recover.

A number of recent studies have focused on the extent of extremely low winter temperatures in the Arctic lower stratosphere (e.g., Pawson and Naujokat, 1999). Extremely low temperatures are required for the formation of polar stratospheric clouds (PSCs), and these conditions have become increasingly widespread in the Arctic over the past half-century (Rex et al., 2004, 2006). This cooling, however, seems to be strongest during the coldest, dynamically undisturbed winters, suggesting that a feedback mechanism of some kind is playing a role. The above-cited studies have focused on the extent of thermodynamically favourable conditions for PSC formation rather than the clouds themselves, in part because a complete understanding of their formation remains elusive.

More importantly, Rex et al. (2004) demonstrated that diagnostics of the thermodynamic conditions for PSC formation in the Arctic correlate very strongly with polar chemical ozone loss, despite the strong non-linearities involved in the activation and destruction mechanisms. The trend in the extent of favourable conditions for PSC formation thus has potentially worrisome implications. If the cooling trend is a result of climate change, then it will continue in the future, potentially leading to a substantial increase in Arctic ozone loss over the next few decades while halogen loading remains high. However, if ozone loss itself is responsible, then the trend could be expected to reverse as the halogen loading subsides.

It is also possible that the apparent trend in the lowtemperature extremes is only a result of interannual variability. The threshold temperature required for PSCs to form is close to the lowest temperatures observed in the Arctic stratosphere, and diagnostics of the cold tails of temperature

Published by Copernicus Publications on behalf of the European Geosciences Union. 


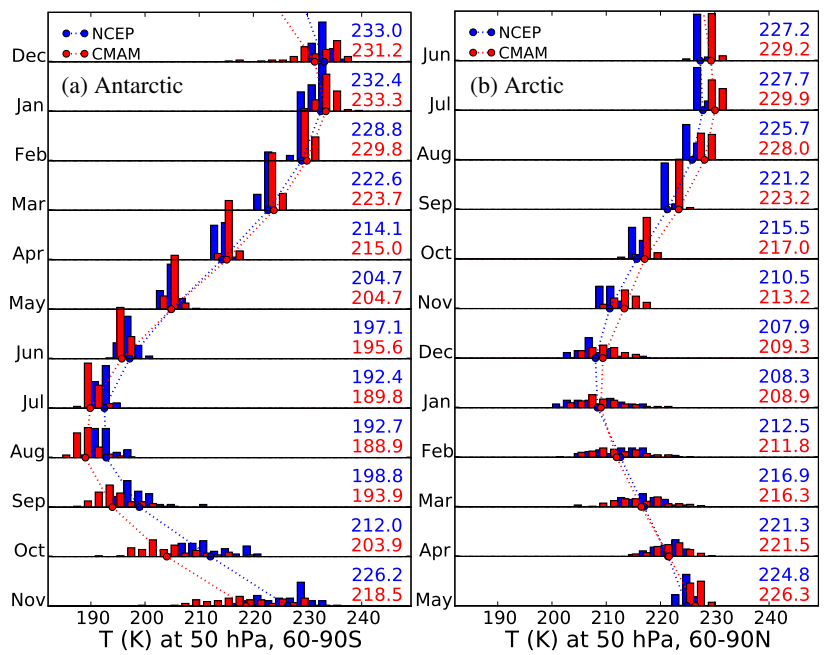

Fig. 1. Histograms of area-weighted monthly mean temperatures from 1979 to 2006 at $50 \mathrm{hPa}$ from the NCEP reanalysis (blue) and CMAM simulations (red) in (a) the Antarctic $\left(60^{\circ}\right.$ to $\left.90^{\circ} \mathrm{S}\right)$ and (b) the Arctic $\left(60^{\circ}\right.$ to $\left.90^{\circ} \mathrm{N}\right)$. Bins are $2 \mathrm{~K}$ in width and are offset slightly for clarity. Climatological means are shown at the right of each panel for the NCEP reanalysis (top) and CMAM data (bottom). They are also indicated by a circle for each month and connected by a dashed line to guide the eye.

distributions are sensitive to the strong dynamical variability of the polar vortex. Identifying and attributing deterministic changes is thus particularly difficult. Since the increase in the extent of these conditions is only apparent in less dynamically active winters, fully characterizing the trend against the strong background of natural variability requires many more years of data than are available in the observational record. It should also be pointed out that the statistical significance of the trend in the coldest years depends on which reanalysis data sets are used (see, for example, Table 1 of Rex et al., 2006 or Fig. A1 of Manney et al., 2005).

With these issues in mind, we discuss here the lowtemperature extremes of the polar stratosphere in an ensemble of three 150-year integrations of the Canadian Middle Atmosphere Model (CMAM), an interactive chemistry-climate model (CCM). The ensemble simulates ozone depletion and recovery and climate change from 1950 to 2100 , forced by observed and projected halogen and greenhouse gas concentrations. The length and size of the ensemble allows for some characterization of the variability of the cold tails of the modelled temperature distributions, as well as a projection of deterministic changes associated with the changing composition of the stratosphere.

Details of the simulations and temperature diagnostics are presented below, followed by an analysis of each hemisphere. Although the emphasis in the literature is on changes in the Arctic, the Antarctic behaviour is more easily under- stood and the differences between the two hemispheres are instructive. We turn first therefore to the Antarctic before considering the Artic behaviour. The paper concludes by discussing the implications of the model results.

\section{Model data}

The version of CMAM used here was run with 71 vertical levels reaching to $97 \mathrm{~km}$ above the surface and T32 spectral truncation $\left(5.6^{\circ} \times 5.6^{\circ}\right.$ linear transform grid $)$. The model includes a comprehensive set of physical parameterizations (Scinocca et al., 2008) and fully interactive stratospheric chemistry (de Grandpré et al., 2000). The ozone chemistry module includes the relevant catalytic ozone loss cycles and heterogeneous reactions on liquid aerosols and water ice, although nitric acid trihydrate (NAT) PSCs and associated denitrification are not parameterized. The rationale for the latter is two-fold. First, there has never been a clear consensus on how to correctly represent NAT formation and sedimentation (see Sect. 4.2.2 of WMO, 2007); indeed Santee et al. (2008) have recently shown that the usual equilibrium models of NAT are quite inaccurate, especially in the Arctic, and that microphysical models (likely prohibitive for a CCM) are required. Second, chlorine activates very effectively on liquid aerosols at low temperatures, which in contrast to NAT are well understood, and which likely account for the majority of the aerosol in the Arctic (Drdla et al., 2002); moreover the effects of denitrification on ozone loss appear to be relatively small, at most 30\% and usually much less (Drdla and Schoeberl, 2002; WMO, 2007).

The ensemble of three runs discussed here were submitted as part of the Stratospheric Processes and Their Role in Climate (SPARC) CCM intercomparison project (CCMVal) and validated against past observations and other models (Eyring et al., 2006). The CMAM projections of ozone and temperature were found to be representative of those from models judged by Eyring et al. $(2006,2007)$ to be generally in good agreement with observations (as indicated by the solid lines in their figures). More detailed plots of the ozone and temperature changes can be found in Shepherd (2008). The three members were forced with different sea-surface temperature and sea-ice time series generated by the Canadian Centre for Climate Modelling and Analysis (CCCma) coupled atmosphere-ocean general circulation model run with the same forcings. The CMAM simulations do not include a quasi-biennial oscillation (forced or internally generated), solar variability, or volcanic forcing.

As a brief validation of polar stratospheric temperature in these runs, distributions of monthly mean polar temperatures from 1979 to 2006 at $50 \mathrm{hPa}$ are shown in Fig. 1 for both CMAM and the National Centers for Environmental Prediction/National Center for Atmospheric Research reanalysis (hereinafter NCEP reanalysis; Kalnay et al., 1996). 
Climatological means for both reanalysis and model data are shown at the right of each panel. Model climatology in the Antarctic agrees with the NCEP reanalysis to within about $1 \mathrm{~K}$ during austral summer and fall (Fig. 1a). However, the Antarctic polar vortex persists for too long in the model spring, resulting in the cold bias in the Southern Hemisphere stratosphere typical of CCMs (Eyring et al., 2006). Model climatologies in the Arctic (Fig. 1b) are warmer than the NCEP reanalysis by about $2 \mathrm{~K}$ through the summer and fall, but with the exception of December agree to better than $1 \mathrm{~K}$ through winter and spring. The shapes of the histograms are roughly consistent between the model and reanalysis for both hemispheres.

\section{Methods}

We use two related diagnostics ( $A_{\mathrm{PSC}}$ and $V_{\mathrm{PSC}}$ ) to measure the extent of favourable conditions for PSC formation, defined similarly to the diagnostics used in Rex et al. (2004, 2006). Since our discussion is qualitative in nature, our conclusions are not sensitive to which diagnostic we use. We define $A_{\mathrm{PSC}}$ as the area poleward of $60^{\circ}$ on a given pressure surface below the equilibrium threshold temperature $T_{\mathrm{NAT}}$ for NAT particles to form. We further define $V_{\mathrm{PSC}}$ as the vertical integral of $A_{\mathrm{PSC}}$ (i.e., the volume of air in the lower polar stratosphere below $\left.T_{\mathrm{NAT}}\right)$. $T_{\mathrm{NAT}}$ is typically about $195 \mathrm{~K}$ in the stratosphere, but the exact value depends on the partial pressures of water vapour and nitric acid (Hanson and Mauersberger, 1988). We assume a constant mixing ratio of 5 ppmv for water vapour and 9 ppbv for nitric acid, neglecting any spatial or temporal variation in either species' mixing ratio. These assumptions result in values for $T_{\mathrm{NAT}}$ very close to those used by Pawson and Naujokat (1999). Earlywinter water vapour mixing ratios in both polar regions of the lower stratosphere increase in these runs by $0.5 \mathrm{ppmv}$ over the twenty-first century (Eyring et al., 2007). If this were included in our analysis, $T_{\mathrm{NAT}}$ would increase by less than $0.5 \mathrm{~K}$ by 2100 and would only minimally affect the figures presented here. It is important to emphasize that $A_{\mathrm{PSC}}$ and $V_{\mathrm{PSC}}$ are intended not as measures of the extent of PSCs that would form given the meteorological conditions of the stratosphere, but rather as proxies for the cold tails of the temperature distributions, and as strong correlates of chemical ozone loss (in present stratospheric conditions). As such, our discussion concerns the response of these cold tails to the observed and projected chemical forcings, not the chemical ozone loss itself.

In order to compare directly with the results of Rex et al. (2004), we discuss $V_{\text {PSC }}$ in the Northern Hemisphere. We adopt a simplified definition of $V_{\mathrm{PSC}}$ based on $A_{\mathrm{PSC}}$ on the $50 \mathrm{hPa}$ and $30 \mathrm{hPa}$ pressure surfaces (denoted $A_{50}$ and $A_{30}$, respectively)

$V_{\mathrm{PSC}}=\left(0.8 A_{50}+0.2 A_{30}\right) \times 5.06 \mathrm{~km}$.

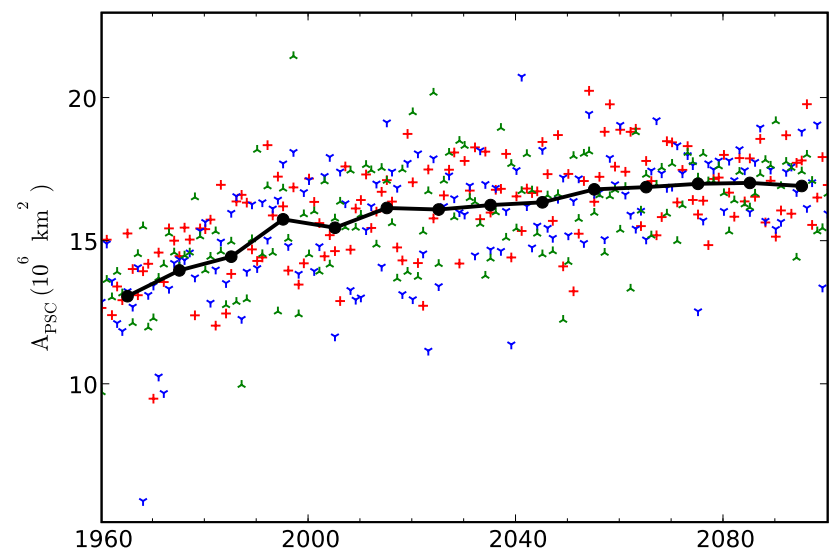

Fig. 2. Time series of $A_{\mathrm{PSC}}$ at $50 \mathrm{hPa}$ in the Antarctic, averaged from May to December for each CMAM simulation. The small symbols indicate individual years, coloured to correspond to the three members of the ensemble, while the black circles indicate the decadal ensemble averages.

The constants were determined by Rex et al. (2004) to give the best fit of Free University of Berlin analysis data (available on a limited number of pressure surfaces) to a more complicated calculation using higher resolution European Centre for Medium-Range Weather Forcasting (ECMWF) analyses and a radiative model. This allows us to compare the CMAM results for the Arctic directly to those of Rex et al. (2004), without needing to duplicate the radiative calculations. Our discussion is predominantly qualitative in nature, and our results are not strongly sensitive to details of these definitions.

In contrast, we focus on $A_{\mathrm{PSC}}$ (rather than $V_{\mathrm{PSC}}$ ) in the Southern Hemisphere for simplicity, and to retain some vertical information. We emphasize in particular the $50 \mathrm{hPa}$ surface as being representative of a region with strong ozone depletion.

To separate the respective effects of ozone depletion/recovery and climate change, we focus on three periods in the model runs: 1960 to 1979 before significant ozone depletion, 1990 to 2009 during the peak of ozone depletion, and 2060 to 2079 after the ozone layer has recovered from the effects of the halogen loading (using the period 2080 to 2099 does not affect any of our discussion). Since there are three members of the ensemble, we have sixty years in each sample. The secular increase in carbon dioxide in the model runs is expected to lead to steady cooling above the troposphere through the whole seasonal cycle, while any climatechange related circulation change at high latitudes would be expected to occur in winter or spring. Effects attributable to ozone depletion should reverse as ozone recovers and should be most evident in spring.

We also present several other diagnostics of polar stratospheric temperatures. Climatologies of daily temperature distributions in the polar lower stratosphere are plotted in 


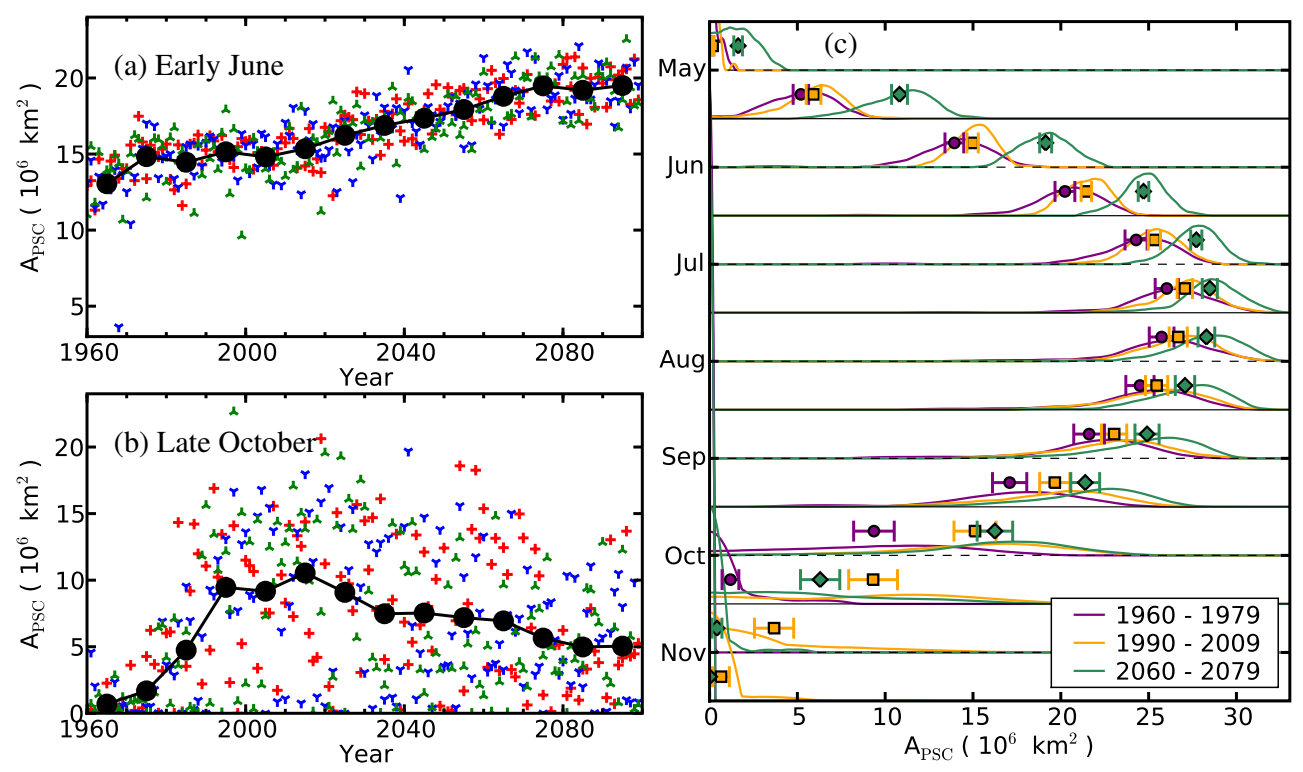

Fig. 3. Time series of $A_{\mathrm{PSC}}$ at $50 \mathrm{hPa}$ in the Antarctic for (a) early June and (b) late October. Individual years from the three runs and decadal ensemble means are indicated as in Fig. 2. (c) Distributions of $A_{\mathrm{PSC}}$ at $50 \mathrm{hPa}$ in the Antarctic at semi-monthly intervals for the periods 1960-1979, 1990-2009 and 2060-2079, estimated using the kernel method. Distributions on the dashed base lines are for the early part of each month, while those on solid base lines are for the latter part of each month. The three periods are colour coded. The means of each distribution are indicated by the solid symbols, with error bars indicating plus and minus twice the standard deviation of the mean.

order to relate $A_{\mathrm{PSC}}$ and $V_{\mathrm{PSC}}$ to monthly, zonal mean temperatures, and in order to emphasize the non-linear nature of the changes in conditions for PSC formation in the Arctic. Changes in polar temperatures due to changes in resolved wave drag in CMAM are also discussed in the context of some standard diagnostics.

Finally, distributions of some quantities are estimated using a kernel density estimation technique (instead of histograms). This method generates continuous distributions which are not sensitive to choices of bin size and position, at the cost of being less familiar and less easily "inverted" by eye. Details on the method can be found in statistics texts such as Silverman (1986). They are used below primarily to demonstrate changes in the distributions of diagnostics over the three periods described above.

\section{Antarctic stratosphere}

Observed temperatures in the Antarctic stratosphere drop below $T_{\mathrm{NAT}}$ for nearly half of the year and extend in the winter over a large fraction of the polar region. In contrast to the situation in the Arctic stratosphere, $A_{\text {PSC }}$ over Antarctica should therefore be robustly sensitive to changes in the climatological mean winter and springtime polar temperatures, and the effects of ozone depletion/recovery and climate change should be evident.
The time series of $A_{\mathrm{PSC}}$ at $50 \mathrm{hPa}$ averaged from May to December is shown in Fig. 2. In each member of the ensemble, $A_{\text {PSC }}$ increases substantially through the 20th century then levels off near the beginning of the 21st century, increasing slightly until the end of the simulations. This transition occurs around the time of peak ozone depletion.

This change in trend is better understood by considering time series of $A_{\mathrm{PSC}}$ as a function of the seasonal cycle. Since the character of the response changes rapidly in the spring, we present semi-monthly averages. The time series of $A_{\mathrm{PSC}}$ in early June (Fig. 3a) exhibits a steady increase in each run. This is consistent with the cooling due to steadily increasing carbon dioxide. In late October (Fig. 3b), however, the response is no longer monotonic with time. $A_{\mathrm{PSC}}$ increases substantially as the ozone hole develops then decreases as ozone recovers, though post-recovery values remain greater than pre-ozone hole values as a result of climate change.

Figure $3 \mathrm{c}$ shows distributions of semi-monthly averages of $A_{\mathrm{PSC}}$ from May through November for the three periods. The distributions are estimated by a kernel density estimation technique with a quadratic kernel (Silverman, 1986). Sample means are indicated by symbols with error bars denoting twice the standard deviation of the mean. Distributions from May through to early October shift steadily to the right with time reflecting the cooling lower Antarctic stratosphere, with nearly all shifts lying outside the error bars. In late October and early November, $A_{\text {PSC }}$ peaks while the ozone hole is present (1990 to 2009), declining by the period of 

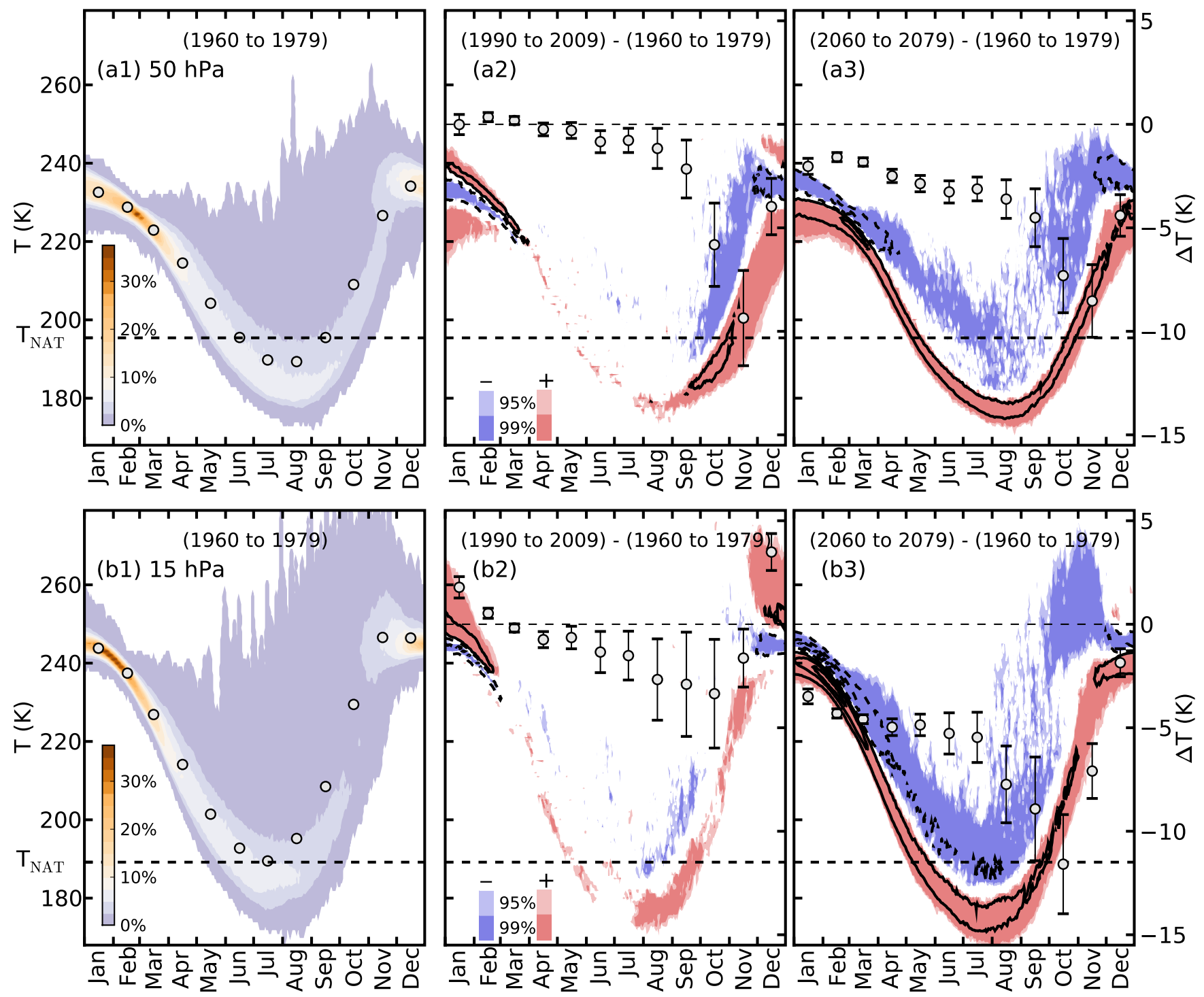

Fig. 4. Climatology of temperature distributions in the Antarctic stratosphere on the (a) $50 \mathrm{hPa}$ and (b) $15 \mathrm{hPa}$ pressure surfaces. The leftmost panels (a1,b1) show the fraction of the polar cap (poleward of $60^{\circ} \mathrm{S}$ ) in each $1 \mathrm{~K}$ temperature bin for the period prior to the ozone hole $(1960$ to 1979), with mean temperatures for each month indicated by circles. The tick marks on the horizontal axes indicate the first of each month. The middle and rightmost panels (a2-3, b2-3) show the difference between the climatology prior to the ozone hole and the climatologies for the ozone-hole period (1990 to 2009) and the post-ozone recovery period (2060 to 2079), respectively. Coloured shading indicates statistically significant changes in the fraction of the polar cap at each temperature, as indicated by the legend in the middle panels. The black contour lines indicate the magnitude of the differences, with dashed lines indicating a decrease. The first contours indicate a change of $2.5 \%$ of the polar cap area per $1 \mathrm{~K}$ bin, after which the contour interval is $10 \%$ per bin. The zero contour is omitted for clarity. The circles in the middle and rightmost panels indicate the change in monthly mean temperatures (note the axis on the right) with error bars indicating 95\% confidence intervals. The heavy dashed line in each panel indicates $T_{\mathrm{NAT}}$. See text for further discussion of the figure panels.

post-ozone recovery (2060 to 2079). The timing of this peak in late spring is consistent with severe chemical ozone loss induced by the spring-time sunlight and the presence of activated chlorine. Cooling due to climate change prevents $A_{\mathrm{PSC}}$ from declining to its pre-ozone-hole levels.
Similar results are found from $100 \mathrm{hPa}$ up to $20 \mathrm{hPa}$, though $A_{\text {PSC }}$ decreases with altitude, and peak values of $A_{\text {PSC }}$ occur earlier in the winter at higher altitudes (not shown). The temporally non-monotonic behaviour associated with changes in ozone in the late spring weakens with 
Table 1. Fitted parameters for linear regressions in Fig. 5. Ranges quoted are $95 \%$ confidence intervals.

\begin{tabular}{ccc}
\hline Period & Slope $\left(\mathrm{K} /\left(\mathrm{K} \mathrm{m} \mathrm{s}^{-1}\right)\right)$ & Intercept $(\mathrm{K})$ \\
\hline 1960 to 1979 & $1.3 \pm 0.4$ & $182 \pm 3$ \\
1990 to 2009 & $1.1 \pm 0.2$ & $183 \pm 2$ \\
2060 to 2079 & $1.1 \pm 0.4$ & $180 \pm 3$ \\
\hline
\end{tabular}

height, while the secular cooling strengthens with height above the tropopause, consistent with qualitative radiative expectations.

To get a better sense of how sensitive $A_{\text {PSC }}$ is to changes in the overall thermal structure of the Antarctic stratosphere, we consider the temperature distribution of the polar cap (south of $60^{\circ} \mathrm{S}$ ). Since $A_{\text {PSC }}$ is sensitive to zonal asymmetries, it is more easily related to temperature distributions than to more standard diagnostics like the zonal mean. Climatologies of the temperature histograms at $50 \mathrm{hPa}$ (top panels) and $15 \mathrm{hPa}$ (bottom panels) for the three periods are shown in Fig. 4. The colour shading in the leftmost panels indicates the fraction of the polar region at each $1 \mathrm{~K}$ temperature bin for each day of the year, as indicated by the colour bars on the left. The tight distributions in the summer months are indicative of the relative quiescence of the summer stratosphere, while the broad distributions in winter and spring reflect the strong spatial and temporal variability associated with the polar vortex. The circles indicate monthly mean temperatures. The dashed line indicates $T_{\mathrm{NAT}}$, so that $A_{\mathrm{PSC}}$ for any given day is given by the area of air below this line. $T_{\mathrm{NAT}}$ is lower at $15 \mathrm{hPa}$ than at $50 \mathrm{hPa}$ as a result of the lower partial pressures of water vapour and nitric acid, which is reflected by the position of the dashed lines in the upper and lower sets of panels.

The middle and rightmost panels of Fig. 4 show the changes during the period of peak ozone depletion and after ozone recovery, respectively. In these panels, the coloured shading indicate statistically significant shifts in the temperature histograms, as measured by a $t$-test at each $1 \mathrm{~K}$ bin. Here, red or blue shading indicates that statistically more or less air is present in the $1 \mathrm{~K}$ temperature bin indicated by the axis on the left. The black contours indicate the magnitude of the difference, with dashed lines indicating negative values. The first interval is $2.5 \%$ of the polar cap area per $1 \mathrm{~K}$ bin; subsequent contours are spaced by $10 \%$. The zero contour line is omitted for clarity. Changes in the monthly mean are indicated by the circles (plotted against the axis on the right), with error bars indicating 95\% confidence intervals. For example, the red shading in Fig. $4 \mathrm{a} 2$ in November indicates that a larger fraction of the polar cap area on the $50 \mathrm{hPa}$ pressure surface lies between roughly $190 \mathrm{~K}$ and $210 \mathrm{~K}$ in the period when ozone is depleted than in the period prior to ozone depletion. Similarly, the blue shading indicates that a smaller fraction of the polar cap area is at temperatures above $220 \mathrm{~K}$. These changes are consistent with the $9 \mathrm{~K}$

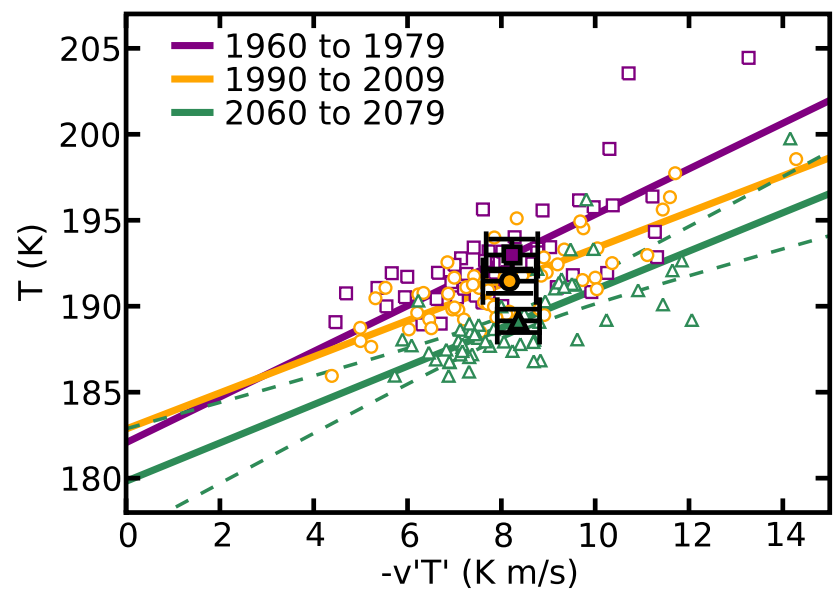

Fig. 5. July-August, $40^{\circ}$ to $80^{\circ} \mathrm{S}$ meridional heat flux $\overline{v^{\prime} T^{\prime}}$ at $100 \mathrm{hPa}$ versus August to September, $60^{\circ}$ to $90^{\circ} \mathrm{S}$ temperatures $\bar{T}$ at $50 \mathrm{hPa}$ for each of the three periods in these simulations (coloured symbols). Error bars on the sample means indicate twice the standard error of the mean. Linear fits are shown as thick lines, and the error in the conditional mean for one fit is indicated by dashed lines.

drop in the monthly mean temperature, while the red shading below $T_{\mathrm{NAT}}$ (the dashed line) indicates that mean $A_{\mathrm{PSC}}$ has increased. In general, red shading below blue shading indicates cooling, while red shading above blue shading indicates warming.

During the period of peak ozone depletion (Fig. 4a2), there is significantly more cold air present at $50 \mathrm{hPa}$ in the spring, consistent with a delay in the break-up of the vortex by nearly a month. By contrast, there is no significant cooling in the early winter (indicated by the absence of shading from April to September in this panel). This is reflected in the changes in the monthly mean temperatures which remain nearly constant from January to August, but cool by $9 \mathrm{~K}$ in November. In October and November this cooling occurs below $T_{\mathrm{NAT}}$, consistent with the strong peaks in $A_{\mathrm{PSC}}$ during this period at this time in the season (see Fig. 3b). Cooling from ozone depletion dominates any signal from climate change in this panel.

At $15 \mathrm{hPa}$ during the period of peak ozone depletion (Fig. 4b2), the cooling in late spring is less pronounced. At higher altitudes it is absent (not shown), consistent with the weakening of the non-monotonic behaviour in the $A_{\mathrm{PSC}}$ time series with height. The vertical extent of this cooling also coincides with that due to ozone loss found by Langematz et al. (2003). At $15 \mathrm{hPa}$ there is substantially more warm air in the early summer than there is in the period before the ozone hole. This warming is due to planetary wave-driven downwelling which can persist for longer due to the delayed break-up of the vortex (Manzini et al., 2003; Stolarski et al., 2006; McLandress and Shepherd, 2009). This occurs well above $T_{\mathrm{NAT}}$ and thus does not affect $A_{\mathrm{PSC}}$. 

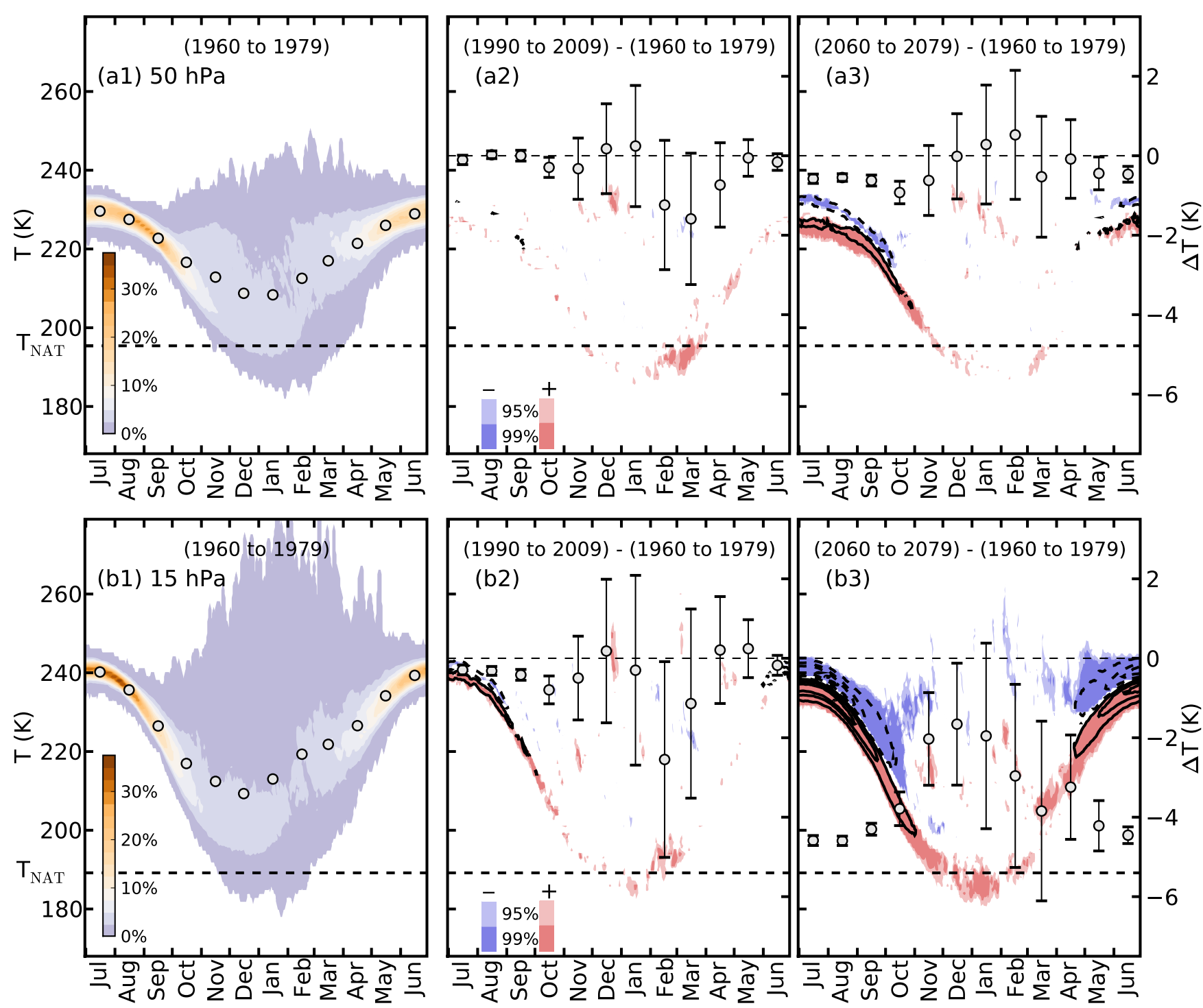

Fig. 6. Same as Fig. 4 but for the climatologies of temperature distributions in the Arctic (poleward of $60^{\circ} \mathrm{N}$ ). The horizontal axis has been shifted six months so that the winter months are centred.

By the end of the 21 st century, ozone recovers in the model and the polar cap has cooled in all seasons (Fig. 4, rightmost panels). The monthly mean cooling is strongest in October and November, again associated with a delay in the break-up of the polar vortex. This long-term cooling is consistent with the radiative effects of increased carbon dioxide. At $50 \mathrm{hPa}$, however, November has warmed with respect to the ozone hole period as a result of increased shortwave heating.

The dynamical contribution to polar temperatures in the lower stratosphere can be estimated using a diagnostic proposed by Newman et al. (2001), and discussed in the context of CCMs by Austin et al. (2003). Late-winter polar cap temperatures at $50 \mathrm{hPa}$ are correlated with the $40^{\circ}$ to $80^{\circ} \mathrm{S}$ averaged meridional heat flux at $100 \mathrm{hPa}$ one month earlier.
The slope of the fit can be interpreted as the efficiency of the dynamical heating, and the intercept can be interpreted as a proxy for the radiatively determined temperatures modified by the effects of parameterized gravity wave drag. Purely radiative effects, therefore, should show up as a shift in the intercept.

This fit is plotted for each of the three periods in Fig. 5. While there is no statistically significant change in either the meridionally-averaged heat flux or the slope of the fit (Table 1), the polar temperatures decrease over the course of the run (as already seen in Fig. 4), indicating the predominately radiative nature of the effects of climate change on modelled Antarctic lower stratosphere temperatures. Although the change in mean polar temperatures is statistically 


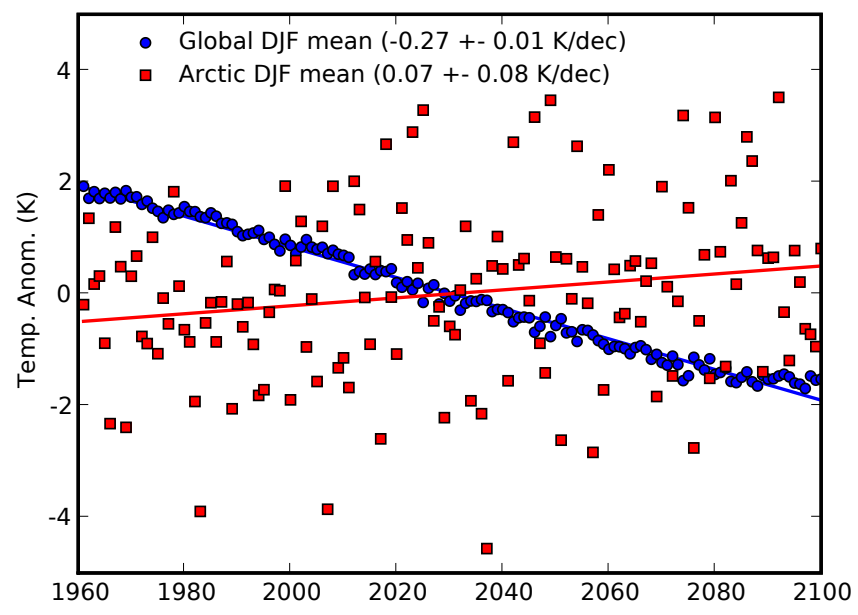

Fig. 7. Ensemble, zonally, December-February (DJF) averaged temperature anomaly at $50 \mathrm{hPa}$. The global anomalies (blue circles) show a steady cooling trend. In contrast the Arctic anomalies (red squares) increase slightly throughout the run, consistent with strengthened polar downwelling. Solid lines indicate linear fits with $95 \%$ confidence intervals for the slopes indicated in the legend.

significant, there are not enough data points to resolve any change in the intercept (as indicated by the dashed lines in Fig. 5 and the confidence intervals in Table 1). Note that a closer inspection indicates that the magnitude of the heat flux does in fact increase steadily with time between $40^{\circ}$ and $60^{\circ} \mathrm{S}$ while it decreases from $60^{\circ} \mathrm{S}$ to the pole such that the $40^{\circ}$ to $80^{\circ} \mathrm{S}$ area-weighted average does not change. A direct inspection of the downwelling over the south pole in August and September indicates that it does not change either, confirming the conclusions drawn from this figure (see McLandress and Shepherd, 2009). The suitability of this type of figure as a diagnostic of the dynamical and radiative aspects of climate change will be discussed in further detail in the next section.

In summarizing this section, we have shown that the cold extremes of the modelled temperature distributions in the Antarctic show clear evidence of the radiative effects of ozone depletion and recovery and of climate change. The strong cooling trend up to the present in the seasonal average of $A_{\text {PSC }}$ (Fig. 3 ) is consistent with the combined effects of reduced ozone and increased carbon dioxide. This trend levels out in the twenty-first century as the continued cooling from climate change is roughly balanced in the seasonal average by the recovery of the ozone layer. We did not find evidence in this analysis of significant changes in the dynamical heating of the lower Antarctic stratosphere due to climate change.

\section{Arctic stratosphere}

The response of low-temperature extremes in the Arctic lower stratosphere is less clear than those in the Antarctic. $T_{\mathrm{NAT}}$ lies close to the minimum temperatures that occur in the winter, so that diagnostics of the conditions for PSC formation are very sensitive to the strong interannual variability. Moreover, the changes in polar temperatures over the course of these simulations are much weaker in the Arctic than in the Antarctic, and the interannual variability in winter temperatures is much greater. Nonetheless, the basic radiative picture of the model Antarctic behaviour provides a basis for comparison.

Figure 6 shows climatologies of the temperature distributions for the area poleward of $60^{\circ} \mathrm{N}$. The distributions are not as broad in the Arctic (Fig. 6, leftmost panels) as they are in the Antarctic (Fig. 4, leftmost panels) because the temperature gradient at the vortex edge is generally weaker. At $50 \mathrm{hPa}$, the distributions during the peak of ozone depletion are nearly unchanged from the pre-depletion period (Fig. 6a2). There is a slight increase in the amount of air just below $T_{\mathrm{NAT}}$ in late February and early March when ozone is most significantly depleted (indicated by the light red shading), though the signal is much weaker than in the Antarctic. This cooling is evident in the monthly means as well, though the cooling is masked by strong variability. No cooling from climate change is evident during this period at $50 \mathrm{hPa}$, but there is a very weak cooling at $15 \mathrm{hPa}$ during the summer months (Fig. 6b2).

After ozone recovers, there is substantial cooling during the summer months at $15 \mathrm{hPa}$, and weaker cooling during the summer months at $50 \mathrm{hPa}$ (Fig. 6, rightmost panels). However, the cooling in the winter months is minimal at $15 \mathrm{hPa}$ and is absent below. In fact, the ensemble mean December to February temperature in the lower stratosphere over the whole Arctic polar cap increases slightly. This is unexpected from radiative considerations alone, and contrasts with the significant drop in globally-averaged winter temperatures in the lower stratosphere (Fig. 7). This result is indicative of enhanced downwelling in the polar cap that is overwhelming the radiative cooling (McLandress and Shepherd, 2009). Further evidence for strengthened polar downwelling is found in Arctic springtime ozone abundances, which are greater at the end of the 21 st century than before ozone depletion (Shepherd, 2008).

The diagnostic of resolved wave-driven dynamical heating of the pole discussed above (see Fig. 5), however, does not show significant changes in the Northern Hemisphere (Fig. 8). While there is some suggestion of increased efficiency in the dynamical heating during the period of peak ozone depletion, the change in the slope is not statistically significant (Table 2), nor is it robust to changes in the definitions of the periods. Indeed, it seems that the regression parameters of this diagnostic are too sensitive to variability to be a useful indicator of climate change in these model 
Table 2. Fitted parameters for linear regressions in Fig. 8. Ranges quoted are $95 \%$ confidence intervals.

\begin{tabular}{ccc}
\hline Period & Slope $\left(\mathrm{K} /\left(\mathrm{K} \mathrm{m} \mathrm{s}^{-1}\right)\right)$ & Intercept $(\mathrm{K})$ \\
\hline 1960 to 1979 & $0.9 \pm 0.3$ & $203 \pm 4$ \\
1990 to 2009 & $1.3 \pm 0.4$ & $196 \pm 5$ \\
2060 to 2079 & $0.9 \pm 0.4$ & $202 \pm 6$ \\
\hline
\end{tabular}

runs. Moreover, detailed examination of the heat flux indicates that, as in the Antarctic, the heat flux between $40^{\circ}$ and $60^{\circ} \mathrm{N}$ increases with time while it decreases poleward of $60^{\circ} \mathrm{N}$, again such that the average over the broader latitude range does not change substantially. Unlike the Antarctic, the downwelling over the Arctic pole increases significantly and steadily in the months relevant to this diagnostic plot throughout these runs, suggesting that it is primarily a response to climate change rather than ozone depletion. These dynamical responses are discussed and quantified in detail in McLandress and Shepherd (2009). This dynamical response to climate change, while evident in other diagnostics, is not made clear by the regressions shown in Fig. 8 .

We turn finally to the model $V_{\mathrm{PSC}}$ on which we focus (instead of $\left.A_{\mathrm{PSC}}\right)$ in order to compare CMAM with the results of Rex et al. (2004, 2006). In contrast to the behaviour of $A_{\text {PSC }}$ in the Antarctic, the time series of $V_{\text {PSC }}$ in late November (Fig. 9a) shows at most a weak monotonic increase, while $V_{\text {PSC }}$ in late February (Fig. 9b) hints marginally at a response to ozone depletion. Figure 9c shows the seasonal breakdown of $V_{\mathrm{PSC}}$ at semi-monthly intervals for each period. Since Arctic winters are much warmer than their Antarctic counterparts, winters with little or no $V_{\text {PSC }}$ are relatively common, and the distributions even during the mid-winter are strongly non-Gaussian (which will tend to make the $t$-test more liberal, in the sense of being more likely to reject the null hypothesis erroneously, i.e., Zwiers and von Storch, 1995). Nonetheless, a pattern similar to that observed in the Southern Hemisphere suggests itself, with a weak, monotonic increase in $V_{\mathrm{PSC}}$ in the early winter but a maximum during the peak of ozone depletion in spring. The changes in the means, however, are generally not statistically significant, with the possible exception of the maximum in late February while ozone is depleted, consistent with the increase in cold air observed in this period in Fig. 6a2. It should, however, be pointed out that the interpretation of the $2 \sigma$ error-bars as a $95 \%$ confidence interval is based on the assumption that the sample means are normally distributed. Since the distribution itself is strongly non-Gaussian, this assumption is questionable despite the Central Limit Theorem.

The seasonal averages (mid-December to March) of $V_{\text {PSC }}$ in the CMAM ensemble are shown for the full model time series in Fig. 10a. As was evident in Fig. 9, the ensemble average shifts little over the twenty-first century. Figure 10b-d

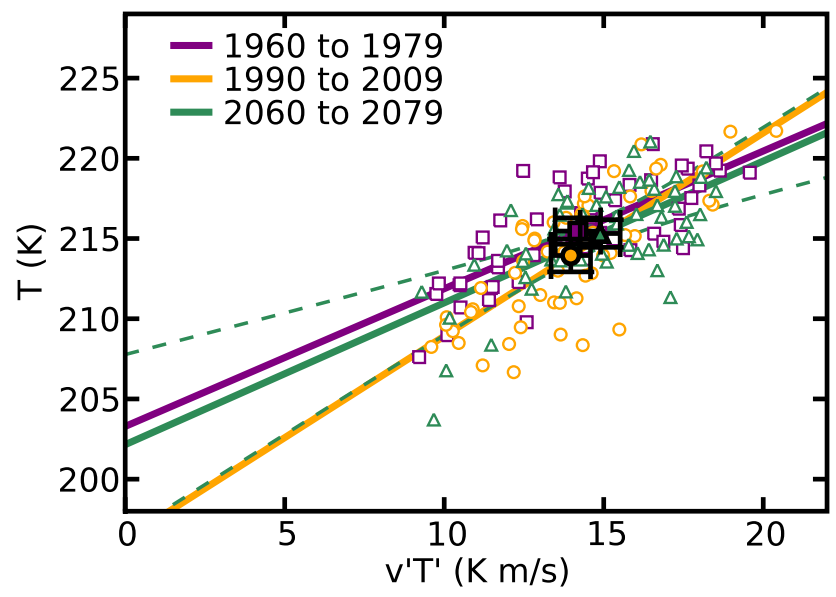

Fig. 8. Same as Fig. 5 but for the Northern Hemisphere; JanuaryFebruary, $40^{\circ}$ to $80^{\circ} \mathrm{N}$ meridional heat flux at $100 \mathrm{hPa}$ versus February-March, $60^{\circ}$ to $90^{\circ} \mathrm{N}$ temperatures at $50 \mathrm{hPa}$ for each of the three periods.

shows the same time series for the latter half of the twentieth century plotted individually against $V_{\mathrm{PSC}}$ calculated from Free University of Berlin (1965 to 1979) and the ECMWF reanalysis (ERA40; Uppala et al., 2005) (1979 to 2001), after Rex et al. (2006). It must be noted that the winter of 2004-2005 (not shown, seasonally averaged $V_{\text {PSC }}$ of about $52 \times 10^{6} \mathrm{~km}^{3}$ ) was extremely cold in the Arctic lower stratosphere, continuing the trend of increasing $V_{\mathrm{PSC}}$ in the coldest years. The linear fit to $V_{\mathrm{PSC}}$ in the coldest years of each time series is shown, with the fitted points highlighted as large symbols. The coldest years are defined as the years with the greatest $V_{\mathrm{PSC}}$ in each five-year interval.

The rough magnitude of $V_{\mathrm{PSC}}$ in CMAM agrees quite well with the observations, consistent with the very close agreement between the model and reanalysis temperature climatology in the Arctic spring (see Fig. 1b). The trends in the extremes in CMAM from 1965-2001, however, are not as strong as the observed trend. The modelled trends are 0.4, 4.4 and $1.3 \times 10^{6} \mathrm{~km}^{3}$ per decade, versus a trend in the reanalysis time series shown here of $6.5 \times 10^{6} \mathrm{~km}^{3}$ per decade (note that this trend is less than reported by Rex et al., 2006 as a result of the different reanalysis product and time period used, and that no error estimates are quoted since the standard estimate of uncertainty in the fitted slope underestimates the true uncertainty of this statistic). One ensemble member (Fig. 10c) produced a trend in the extremes of similar magnitude to the observations while the other two produced very weak positive trends, giving some indication of the strong sensitivity of this trend to the internal variability of the model. Neither are the trends as robust to changes in the length or offset of the intervals used to define the coldest years. An estimation of the statistical significance of the model trends with a Monte Carlo technique similar to that 


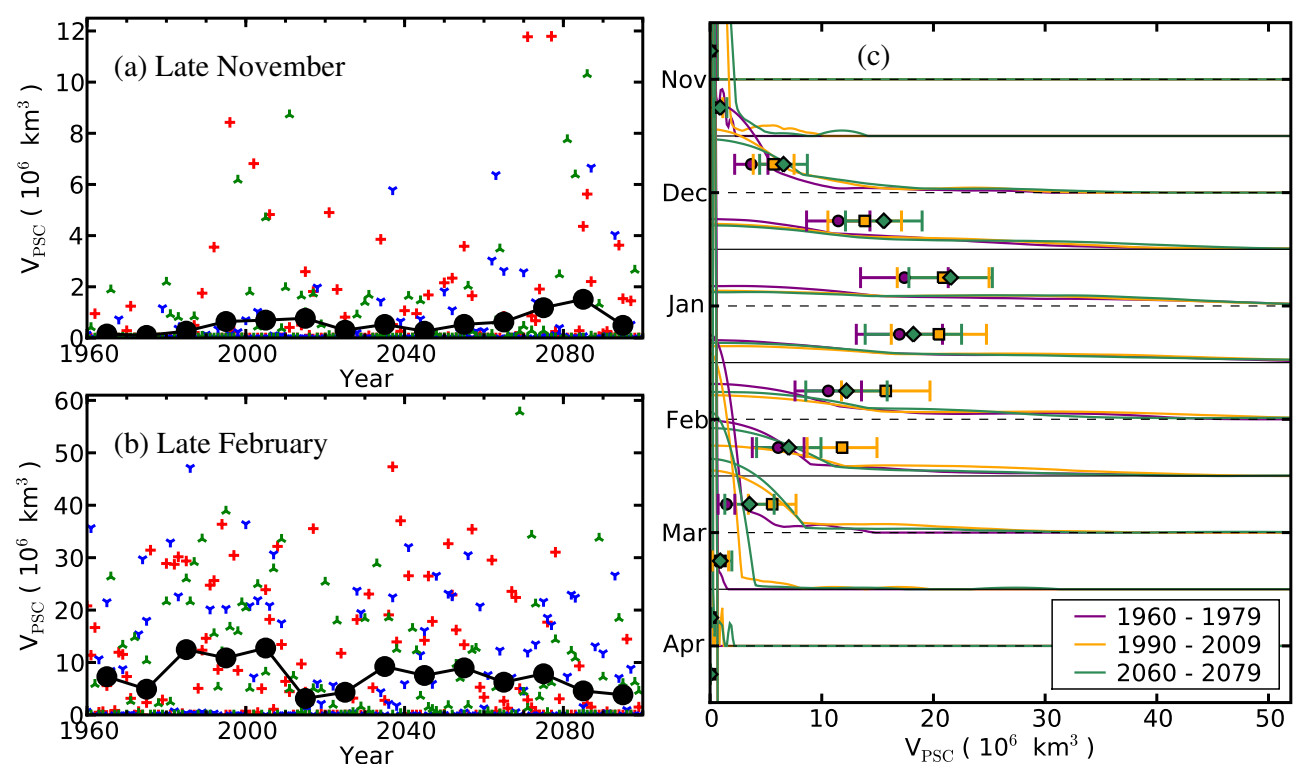

Fig. 9. Time series of $V_{\mathrm{PSC}}$ in the Arctic for (a) late November and (b) late February. Individual years from the three runs and decadal ensemble means are indicated as in Fig. 2. (c) Distributions of $V_{\mathrm{PSC}}$ at semi-monthly intervals for the periods 1960-1979, 1990-2009 and 2060-2079, estimated using the kernel method. An image method is used to ensure the estimated distributions are non-negative (Silverman, 1986). The means of each distribution are indicated by the solid symbols, with error bars indicating plus and minus twice the standard deviation of the mean.

described in Rex et al. (2006) confirms these assertions. One point which supports the validity of this Monte Carlo procedure is that there was no indication of serial correlation in $V_{\text {PSC }}$ in these runs (the lag-one autocorrelation of the raw time series is very close to zero). This autocorrelation cannot be determined reliably from the observational dataset since its variance increases significantly over time. In any case, what trend there is in each of the model runs does not continue into the 21st century (Fig. 10a).

\section{Summary and discussion}

The extent of extremely low temperatures in the Antarctic lower stratosphere increases in the CMAM runs during the latter half of the 20th century, but levels out through the 21st (Fig. 2). This response is clearly understood through qualitative radiative considerations. The initial increase in $A_{\mathrm{PSC}}$ is a combined result of cooling due to both ozone depletion and climate change. As ozone recovers in the twenty-first century the warming in late spring balances the continued cooling earlier in the winter (Fig. 3), and the trend in the seasonal mean $A_{\mathrm{PSC}}$ levels off. The behaviour of the low temperature extremes closely reflects changes in the mean temperatures (Fig. 4).

The behaviour in the Northern Hemisphere in these runs, however, is less obviously interpreted. In strong contrast with the tropospheric response to increased greenhouse gases, mean model temperatures in the Arctic lower stratosphere change little over the next century. A slight cooling in late winter is evident at the peak of ozone depletion. This results in a slight increase of $V_{\mathrm{PSC}}$ in the late winter which reverses as ozone recovers, though these changes are difficult to distinguish definitively from natural variability (Fig. 9). The model response to Arctic ozone depletion is similar in character if not in magnitude to the response to Antarctic ozone depletion. Although cooling is observed in the Northern Hemisphere summer by the end of the simulations, climate change in the winter is compensated by an increase in the strength of dynamically driven downwelling over the pole (Figs. 6, 7).

Note that while there are circulation changes in both hemispheres associated with changes in wave activity fluxes, the latter changes are not detectable in the usual $\overline{v^{\prime} T^{\prime}}$ versus $\bar{T}$ plot (Figs. 5, 8) because of cancelling effects between different latitude bands (McLandress and Shepherd, 2009).

Although the model reproduces the reanalysis temperature climatologies quite well in the Arctic, the trend in the extremes of $V_{\text {PSC }}$ produced by the ensemble members is neither as strong nor as robust as the observed trend. If there is a deterministic change in the extremes in the model, it does not impact the mean (that is, if anything, the variance increases). This contrasts with the Antarctic behaviour. The increase in variance does not continue into the 21 st century, suggesting that ozone depletion plays a role in the model response (Fig. 10). 

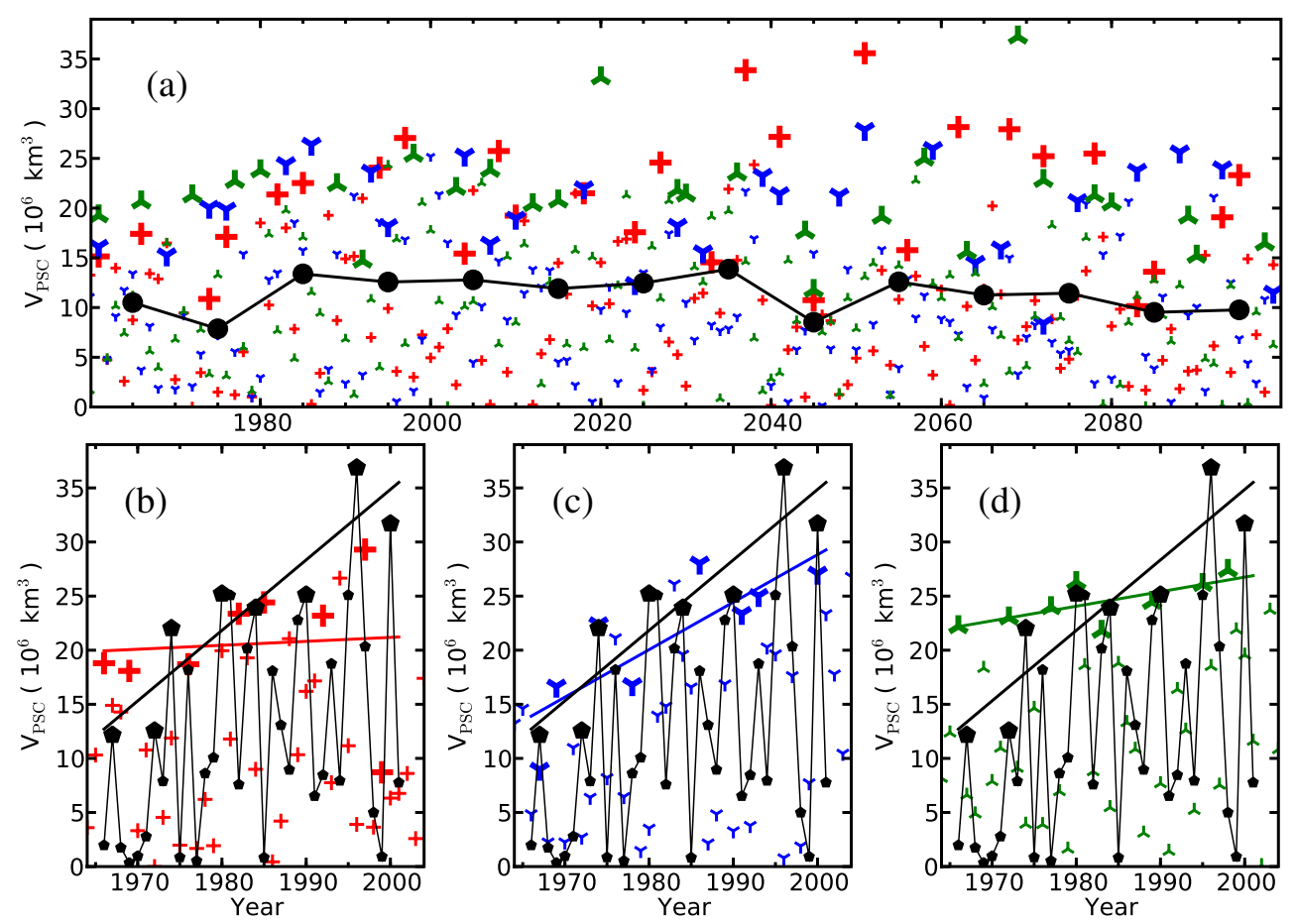

Fig. 10. Time series of seasonally averaged (mid-December to March) $V_{\mathrm{PSC}}$. (a) Full model time series, from 1960 to 2100 . Individual years from each run are colour-coded, with the "coldest year" (see text for definition) in successive five-year intervals indicated by larger symbols. The year reported is that in which January falls. The decadal ensemble average is indicated by black circles as in Fig. 2. (b-d) The same time series up to 2003, plotted after Rex et al. (2006). V VSC calculated from the Free University of Berlin analysis and ERA40 reanalysis is shown in black. Each member of the CMAM ensemble is plotted individually in colour against the reanalysis data. Large symbols again indicate the "coldest year" in five-year intervals from 1966 to 2001 and are used to calculate the regression lines.

One reason the model may not generate a trend in the Arctic low-temperature extremes as strong as is observed is that Arctic ozone was not depleted sufficiently in these runs (Shepherd, 2008; Tegtmeier and Shepherd, 2007). A possible reason for this is that these runs did not include a parameterization of NAT PSCs or the associated denitrification, which would be expected to enhance ozone depletion. With stronger ozone depletion we would expect a stronger model trend in low-temperature extremes in the past, perhaps enough to match the observations. This reasoning, together with the Antarctic behaviour, supports (though certainly does not prove) the hypothesis that the observed Arctic trend is mainly the result of ozone depletion, in which case it cannot be expected to continue in the future.

Rex et al. (2004, 2006) suggest the observed trend is due to climate change. They estimate the linear response in $V_{\text {PSC }}$ to be $7.7 \pm 2.6 \times 10^{6} \mathrm{~km}^{3} \mathrm{~K}^{-1}$ of cooling in the Arctic (Rex et al., 2004), which, for an observed trend in $V_{\mathrm{PSC}}$ of $9.9 \pm 1.1 \times 10^{6} \mathrm{~km}^{3}$ per decade (Rex et al., 2006), would require a cooling of roughly $1 \mathrm{~K}$ per decade. As noted earlier, CMAM shows if anything a long-term warming. A comparison of CCM estimates of long-term winter temperature trends in the Arctic stratosphere shows essentially no significant trends at $50 \mathrm{hPa}$, with most CCMs showing if anything a warming rather than a cooling (Eyring et al., 2007, Table 2); the four models which exhibit a cooling were among those judged by Eyring et al. $(2006,2007)$ as not generally in good agreement with observations. However, it is certainly possible that these CCMs may all be wrong in this respect. There is not yet a clear consensus on the dynamical response to climate change in the Arctic stratosphere.

The final possibility to be considered is that the observed trend reflects natural variability. It is true that one of the ensemble members exhibited a trend in $V_{\text {PSC }}$ extremes over the late 20th century that is similar in magnitude to the observed trend while the other two ensemble members produced only very weak trends, which suggests that natural variability could be a significant contributor to the observed trend. However, because CMAM has insufficient Arctic ozone depletion, it therefore likely underestimates variability in low temperature extremes. Moreover these CMAM simulations are missing natural sources of variability such as the quasi-biennial oscillation, solar variability, and volcanic eruptions. Finally, the limited number of ensemble members 
makes it difficult to quantify the statistics of "the coldest winters." For all these reasons, these simulations do not provide much guidance on whether natural variability could explain the observed trend.

Acknowledgements. This research has been supported by the Natural Sciences and Engineering Research Council through a scholarship to the first author and by the Canadian Foundation for Climate and Atmospheric Sciences. The authors thank John Austin and an anonymous reviewer for their helpful comments and Michelle Santee for useful discussions.

Edited by: W. Lahoz

\section{References}

Austin, J., Shindell, D., Beagley, S. R., Brühl, C., Dameris, M., Manzini, E., Nagashima, T., Newman, P., Pawson, S., Pitari, G., Rozanov, E., Schnadt, C., and Shepherd, T. G.: Uncertainties and assessments of chemistry-climate models of the stratosphere, Atmos. Chem. Phys., 3, 1-27, 2003,

http://www.atmos-chem-phys.net/3/1/2003/.

de Grandpré, J., Beagley, S. R., Fomichev, V. I., Griffioen, E., McConnell, J. C., Medvedev, A. S., and Shepherd, T. G.: Ozone climatology using interactive chemistry: Results from the Canadian Middle Atmosphere Model, J. Geophys. Res., 105, 2647526491, 2000.

Drdla, K. and Schoeberl, M. R.: Microphysical modeling of the 1999-2000 Arctic winter 2. Chlorine activation and ozone depletion, J. Geophys. Res., 108, 8319, doi:10.1029/2001JD001159, 2002.

Drdla, K., Gandrud, B. W., Baumgardner, D., Wilson, J. C., Bui, T. P., Hurst, D., Schauffler, S. M., Jost, H., Greenblatt, J. B., and Webster, C. R.: Evidence for the widespread presence of liquidphase particles during the 1999-2000 Arctic winter, J. Geophys. Res., 108, 8318, doi:10.1029/2001JD001127, 2002.

Eyring, V., Butchart, N., Waugh, D. W., Akiyoshi, H., Austin, J., Bekki, S., Bodeker, G. E., Boville, B. A., Brühl, C., Chipperfield, M. P., Cordero, E., Dameris, M., Deushi, M., Fioletov, V. E., Frith, S. M., Garcia, R. R., Gettelman, A., Giorgetta, M. A., Grewe, V., Jourdain, L., Kinnison, D. E., Mancini, E., Manzini, E., Marchand, M., Marsh, D. R., Nagashima, T., Newman, P. A., Nielsen, J. E., Pawson, S., Pitari, G., Plummer, D. A., Rozanov, E., Schraner, M., Shepherd, T. G., Shibata, K., Stolarski, R. S., Struthers, H., Tian, W., and Yoshiki, M.: Assessment of temperature, trace species, and ozone in chemistry-climate model simulations of the recent past, J. Geophys. Res., 111, D22308, doi:10.1029/2006JD007327, 2006.

Eyring, V., Waugh, D. W., Bodeker, G. E., Cordero, E., Akiyoshi, H., Austin, J., Beagley, S. R., Boville, B. A., Braesicke, P., Brühl, C., Butchart, N., Chipperfield, M. P., Dameris, M., Deckert, R., Deushi, M., Frith, S. M., Garcia, R. R., Gettelman, A., Giorgetta, M. A., Kinnison, D. E., Mancini, E., Manzini, E., Marsh, D. R., Matthes, S., Nagashima, T., Newman, P. A., Nielsen, J. E., Pawson, S., Pitari, G., Plummer, D. A., Rozanov, E., Schraner, M., Scinocca, J. F., Semeniuk, K., Shepherd, T. G., Shibata, K., Steil, B., Stolarski, R. S., Tian, W., and Yoshiki, M.: Multimodel projections of stratospheric ozone in the 21st century, J. Geophys. Res., 112, D16303, doi:10.1029/2006JD008332, 2007.
Hanson, D. R. and Mauersberger, K.: Laboratory studies of the nitric acid trihydrate: Implications for the south polar stratosphere, J. Geophys. Res., 15, 855-858, 1988.

Kalnay, E., Kanamitsu, M., Kistler, R., Collins, W., Deaven, D., Gandin, L., Iredell, M., Saha, S., White, G., Woollen, J., Zhu, Y., Leetmaa, A., Reynolds, R., Chelliah, M., Ebisuzaki, W., Higgins, W., Janowiak, J., Mo, K., Ropelewski, C., Wang, J., Jenne, R., and Joseph, D.: The NCEP/NCAR 40-Year reanalysis project, Bull. Amer. Meteor. Soc., 77, 437-471, 1996.

Langematz, U., Kunze, M., Krüger, K., Labitzke, K., and Roff, G. L.: Thermal and dynamical changes of the stratosphere since 1979 and their link to ozone and $\mathrm{CO}_{2}$ changes, J. Geophys. Res., 108(D1), 4027, 2003.

Manney, G. L., Krüger, K., Sabutis, J. L., Sena, S. A., and Pawson, S.: The remarkable 2003-2004 winter and other recent warm winters in the Arctic stratosphere since the late 1990s, J. Geophys. Res., 110, D04107, doi:10.1029/2004JD005367, 2005.

Manzini, E., Steil, B., Brühl, C., Giorgetta, M. A., and Krüger, K.: A new interactive chemistry-climate model: 2. Sensitivity of the middle atmosphere to ozone depletion and increase in greenhouse gases and implications for recent stratospheric cooling, J. Geophys. Res., 108, 4429, doi:10.1029/2002JD002977, 2003.

McLandress, C. and Shepherd, T. G.: Simulated anthropogenic changes in the Brewer-Dobson circulation, including its extension to high latitudes, J. Clim., in press, 2009.

Newman, P. A., Nash, E. R., and Rosenfield, J.: What controls the temperature of the Arctic stratosphere during spring?, J. Geophys. Res., 106, 19999-20010, 2001.

Pawson, S. and Naujokat, B.: The cold winters of the middle 1990s in the northern lower stratosphere, J. Geophys. Res., 104, 1420914222, 1999.

Rex, M., Salawitch, R. J., von der Gathen, P., Harris, N. R. P., Chipperfield, M. P., and Naujokat, B.: Arctic ozone loss and climate change, Geophys. Res. Lett., 31, L04116, doi:10.1029/ 2003GL018844, 2004.

Rex, M., Salawitch, R. J., Deckelmann, H., von der Gathen, P., Harris, N. R. P., Chipperfield, M. P., Naujokat, B., Reimer, E., Allaart, M., Andersen, S. B., Bevilacqua, R., Braathen, G. O., Claude, H., Davies, J., Backer, H. D., Dier, H., Dorokhov, V., Fast, H., Gerding, M., Godin-Beekmann, S., Hoppel, K., Johnson, B., Kyrö, E., Litynska, Z., Moore, D., Nakane, H., Parrondo, M. C., Jr., A. D. R., Skrivankova, P., Stübi, R., Viatte, P., Yushkov, V., and Zerefos, C.: Arctic winter 2005: Implications for stratospheric ozone loss and climate change, Geophys. Res. Lett., 33, L23808, doi:10.1029/2006GL026731, 2006.

Santee, M. L., MacKenzie, I. A., Manney, G. L., Chipperfield, M. P., Bernath, P. F., Walker, K. A., Boone, C. D., Froidevaux, L., Livesey, N. J., and Waters, J. W.: A study of stratospheric chlorine partitioning based on new satellite measurements and modeling, J. Geophys. Res., 113, D12307, doi:10. 1029/2007JD009057, 2008.

Scinocca, J. F., McFarlane, N. A., Lazare, M., Li, J., and Plummer, D.: The CCCma third generation AGCM and its extensions into the middle atmosphere, Atmos. Chem. Phys., 8, 7055-7074, 2008 ,

http://www.atmos-chem-phys.net/8/7055/2008/.

Shepherd, T. G.: Dynamics, stratospheric ozone, and climate change, Atmos.-Ocean, 46, 117-138, 2008.

Silverman, B. W.: Density Estimation for Statistics and Data Anal- 
ysis, Chapman and Hall, 175 pp., 1986.

Stolarski, R. S., Douglass, A. R., Gupta, M., Newman, P. A., Pawson, S., Schoeberl, M. R., and Nielsen, J. E.: An ozone increase in the Antarctic summer stratosphere: A dynamical response to the ozone hole, Geophys. Res. Lett., 33, L21805, doi: 10.1029/2006GL026820, 2006.

Tegtmeier, S. and Shepherd, T. G.: Persistence and photochemical decay of springtime total ozone anomalies in the Canadian Middle Atmosphere Model, Atmos. Chem. Phys., 7, 485-493, 2007, http://www.atmos-chem-phys.net/7/485/2007/.

Uppala, S. M., Kållberg, P. W., Simmons, A. J., Andrae, U., Bechtold, V. D. C., Fiorino, M., Gibson, J. K., Haseler, J., Hernandez, A., Kelly, G. A., Li, X., Onogi, K., Saarinen, S., Sokka, N., Allan, R. P., Andersson, E., Arpe, K., Balmaseda, M. A., Beljaars, A. C. M., Berg, L. V. D., Bidlot, J., Bormann, N., Caires, S., Chevallier, F., Dethof, A., Dragosavac, M., Fisher, M., Fuentes, M., Hagemann, S., Hólm, E., Hoskins, B. J., Isaksen, L., Janssen, P. A. E. M., Jenne, R., Mcnally, A. P., Mahfouf, J.-F., Morcrette, J.-J., Rayner, N. A., Saunders, R. W., Simon, P., Sterl, A., Trenberth, K. E., Untch, A., Vasiljevic, D., Viterbo, P., and Woollen, J.: The ERA-40 re-analysis, Q. J. Roy. Meteor. Soc., 131, 29613012, doi:10.1256/qj.04.176, 2005.
WMO: Scientific Assessment of Ozone Depletion: 2006, WMO Global Ozone Research and Monitoring Project-Report No. 50, Geneva, Switzerland, 2007.

Zwiers, F. W. and von Storch, H.: Taking serial correlation into account in tests of the mean, J. Clim., 8, 336-351, 1995. 